Danielle Allard, University of Manitoba, Winnipeg, MB, Canada

Lisa Quirke,

Faculty of Information, University of Toronto, Toronto, ON, Canada

\title{
BEYOND INFORMATION ACCESS: ASSESSING THE MIGRATION INFORMATION PRACTICES OF DIVERSE NEWCOMER COMMUNITIES TO CANADA TO CUSTOMIZE SETTLEMENT INFORMATION PROVISION (Paper)
}

\begin{abstract}
:
Drawing from research with Afghan refugee youth in Toronto, Ontario, and Filipino permanent residents in Winnipeg, Manitoba, this paper examines newcomer information practices during migration and settlement, suggesting that how newcomer communities engage with settlement information has direct implications for the methods that information professionals might use to reach them.
\end{abstract}

\section{Résumé:}

\section{Introduction}

It is well known that access to relevant information is a critical component for immigrant adaptation and social inclusion into receiving countries for new immigrants (Caidi, Allard \& Quirke, 2010; Caidi \& Allard, 2005). Within Information Studies, research identifies the importance for newcomers (including refugees, permanent residents, and temporary foreign workers) recently arrived to an unknown "culturally alien information environment" (Mehra \& Papajohn, 2007) to access information that helps them live, adapt, and settle into their new location (Fisher et al., 2004; Lloyd et al., 2013). To facilitate this process, information and resource provision services are offered by receiving country governments, the settlement sector, and information institutions such as libraries. Alongside these official channels of information, newcomers are also often exposed to settlement information through a variety of informal avenues such as already migrated friends and family, and social media platforms such as Facebook and Twitter (Komito, 2011). Information from these channels does not always "match" official sources. Indeed, settlement information, but also advice, support, other migrants' stories of migration, and the social and cultural expectations that newcomers encounter within their social networks may confirm, augment, defy, or contradict official sources of information. Newcomers must therefore navigate complex, sometimes contradictory, systems of information as they engage in the critical work of settlement.

This comparative case study (Yin, 2014) highlights the findings of two Canadian-based qualitative studies, one with Afghan youth in Toronto, Ontario, and the other, Filipino newcomers to Winnipeg, Manitoba. In particular, it focuses on the commonalities and significant differences in the information practices (Savolainen, 2008) and the processes 
for each group of finding, using, and sharing information during migration and settlement. Using ethnographic methods including participant observation and in-depth interviews, Quirke's study examined the information practices of Afghan youth arrived to Toronto as refugees, often arriving to Canada alone and via complicated and circuitous routes. Allard conducted multiple in-depth interviews with newcomers arrived to Manitoba from the Philippines as permanent residents under the Manitoba Provincial Nominee Program (MPNP). Respondents were typically well-educated and English language proficient, middle-class professionals. As part of their admittance to the MPNP, they were required to submit signed affidavits by friends and family living in Manitoba who agreed to support their nomination; thus social network support was built into their application process. Within each study, data were transcribed and then analyzed using the grounded theory approach advocated by Emerson, Fretz and Shaw (1995). This first involved the process of open coding, then subsequent rounds of focused coding, which identified findings relevant to topics such as information seeking, sharing, and use, premigration contexts, and settlement resources and experiences. For the purposes of this paper, findings from each study were then examined comparatively, specifically around the issues of migrants' immigration status, pre-migration experiences, and early arrival settlement and information practices.

Comparatively, migrants from the Philippines arrived to Canada with significantly more social, cultural, and economic capital than the Afghan youth. For numerous reasons however, both groups struggled to find and make use of relevant information for settlement. Indeed, comparing the information practices and related settlement experiences of both populations reveal a myriad of factors that mediate newcomers' experiences with information. Not only did these factors influence the accessibility of information, they also profoundly affected how information was sought, selected, and used. Thus, our studies confirm that while improving access to settlement information is indeed of utmost concern (particularly for refugee youth), it is also critically important to consider how newcomers understand and make sense of the various, sometimes contradictory, information sources to which they do have access. This paper identifies and unpacks three distinct aspects of participants' migration context, including: the premigration context (push and pull factors related to migration), the migration policy doors through which newcomers arrive to Canada (refugees vs. landed migrants), and the settlement sector and policy landscape to which respondents arrive. Recognizing that immigration status and settlement experiences have a profound impact on those engaged in both movement and settlement, this paper considers how we might identify and understand migration related contextual factors to articulate the complex information landscape of diverse and marginalized populations whose information and cultural environments are transnational and in profound transition.

Not only do pre-migration and early arrival contextual dimensions significantly impact newcomers' ongoing settlement process, they are essential factors for consideration by librarians and information professionals serious about developing effective information provision strategies for newcomers. Typically, information provision has happened within the confines of libraries, though increasingly, information professionals are taking a broader view of this responsibility. The newcomer populations in our studies do not use libraries at all and are sometimes discouraged from using other institutional resources, such as the settlement sector, by their network ties. We therefore conclude by considering how information professionals might use a-typical information provision and sharing strategies to reach newcomer populations. Strategies include intervening in unofficial 
information channels such as newcomer social networks, and targeting information provision to community based social and leisure events, and through social media. We also consider multi-stakeholder partnering with community organizations and/or the settlement sector. Determining how best to provide services requires that information professionals adopt new interdisciplinary strategies and partnerships that reflect the changing and growing field of information service provision to marginalized and vulnerable community groups.

\section{Reference List:}

Caidi, N., \& Allard, D. (2005). Social inclusion of newcomers to Canada: An information problem? Library \& Information Science Research, 27(3), 302-324. doi:

10.1016/j.lisr.2005.04.003

Caidi, N., Allard, D., \& Quirke, L. (2010). Information practices of immigrants. Annual review of information science and technology, 44(1), 491-531.

Emerson, R. M., Fretz, R. I. \& Shaw, L. L. (1995). Writing ethnographic fieldnotes. Chicago: University of Chicago Press.

Fisher, K., Marcoux, E., Miller, L. S., Sánchez, A., \& Cunningham, E. R. (2004). Information behaviour of migrant Hispanic farm workers and their families in the Pacific Northwest. Information Research, 10(1). Retrieved from http://InformationR.net/ir/101/paper199.html

Komito, L. (2011). Social media and migration: virtual community 2.0. Journal of the American Society for Information Science and Technology, 62(6), 1075-1086.

Lloyd, A., Kennan, M. A., Thompson, K. M., \& Qayyum, A. (2013). Connecting with new information landscapes: information literacy practices of refugees. Journal of Documentation, 69(1), 121-144.

Mehra, B., \& Papajohn, D. (2007). “Glocal” patterns of communication-information convergences in Internet use: Cross-cultural behavior of international teaching assistants in a culturally alien information environment. The International Information \& Library Review, 39(1), 12-30.

Savolainen, R. (2008). Everyday information practices : a social phenomenological perspective. Toronto: Scarecrow Press.

Yin, R. K. (2014). Case study research: Design and methods. Los Angeles: SAGE Publications Inc. 